\title{
Clinical and biochemical indexes from 2019-nCoV infected patients linked to viral loads and lung injury
}

\author{
Yingxia Liu $^{1{ }^{\dagger *}}$, Yang Yang $^{1 \dagger}$, Cong Zhang ${ }^{2,3 \dagger}$, Fengming Huang ${ }^{3 \dagger}$, Fuxiang Wang ${ }^{1}$, Jing Yuan ${ }^{1}$, \\ Zhaoqin Wang ${ }^{1}$, Jinxiu Li ${ }^{1}$, Jianming $\mathrm{Li}^{1}$, Cheng Feng ${ }^{1}$, Zheng Zhang ${ }^{1}$, Lifei Wang ${ }^{1}$, \\ Ling Peng ${ }^{1}$, Li Chen ${ }^{1}$, Yuhao Qin ${ }^{3}$, Dandan Zhao ${ }^{3}$, Shuguang $\operatorname{Tan}^{4}$, Lu Yin ${ }^{5}$, Jun Xu', \\ Congzhao Zhou ${ }^{2}$, Chengyu Jiang ${ }^{3 *}$ \& Lei Liu ${ }^{1 *}$ \\ ${ }^{1}$ Shenzhen Key Laboratory of Pathogen and Immunity, National Clinical Research Center for Infectious Disease, State Key Discipline of \\ Infectious Disease, Shenzhen Third People's Hospital, Second Hospital Affiliated to Southern University of Science and Technology, Shenzhen \\ 518112, China: \\ ${ }^{2}$ Hefei National Laboratory for Physical Sciences at the Microscale and School of Life Sciences, University of Science and Technology of \\ China, Hefei 230027, China; \\ ${ }^{3}$ State Key Laboratory of Medical Molecular Biology, Institute of Basic Medical Sciences, Chinese Academy of Medical Sciences, Department \\ of Biochemistry, Peking Union Medical College, Beijing 100005, China; \\ ${ }^{4}$ Institute of Microbiology, Chinese Academy of Sciences, Beijing 100101, China; \\ ${ }^{5}$ Emergence Department Peking Union Medical College Hospital, Beijing 100731, China
}

Received February 5, 2020; accepted February 8, 2020; published online February 9, 2020

\begin{abstract}
The outbreak of the 2019-nCoV infection began in December 2019 in Wuhan, Hubei province, and rapidly spread to many provinces in China as well as other countries. Here we report the epidemiological, clinical, laboratory, and radiological characteristics, as well as potential biomarkers for predicting disease severity in 2019-nCoV-infected patients in Shenzhen, China. All 12 cases of the 2019-nCoV-infected patients developed pneumonia and half of them developed acute respiratory distress syndrome (ARDS). The most common laboratory abnormalities were hypoalbuminemia, lymphopenia, decreased percentage of lymphocytes (LYM) and neutrophils (NEU), elevated C-reactive protein (CRP) and lactate dehydrogenase (LDH), and decreased CD8 count. The viral load of 2019-nCoV detected from patient respiratory tracts was positively linked to lung disease severity. ALB, LYM, LYM (\%), LDH, NEU (\%), and CRP were highly correlated to the acute lung injury. Age, viral load, lung injury score, and blood biochemistry indexes, albumin (ALB), CRP, LDH, LYM (\%), LYM, and NEU (\%), may be predictors of disease severity. Moreover, the Angiotensin II level in the plasma sample from 2019-nCoV infected patients was markedly elevated and linearly associated to viral load and lung injury. Our results suggest a number of potential diagnosis biomarkers and angiotensin receptor blocker (ARB) drugs for potential repurposing treatment of 2019-nCoV infection.
\end{abstract}

2019-nCoV, Angiotensin II, ARDS

Citation: $\quad$ Liu, Y., Yang, Y., Zhang, C., Huang, F., Wang, F., Yuan, J., Wang, Z., Li, J., Li, J., Feng, C., et al. (2020). Clinical and biochemical indexes from 2019$\mathrm{nCoV}$ infected patients linked to viral loads and lung injury. Sci China Life Sci 63, 364-374. https://doi.org/10.1007/s11427-020-1643-8 


\section{INTRODUCTION}

In December 2019, a cluster of pneumonia cases linked to the Wuhan seafood wholesale market were reported and found to be caused by 2019 novel coronavirus (2019-nCoV), the seventh member of the coronavirus family that infects humans (Huang et al., 2020; Li et al., 2020; Tan, 2020). A possible person-to-person spread was identified when a cluster of 2019-nCoV patients with Wuhan traveling records emerged in more cities in China (Li et al., 2020; Huang et al., 2020). By Feb 2 of 2020, 11,901 cases were laboratory confirmed and 259 died (National Health Commission Update on February 02, 2020, http://www.nhc.gov.cn/xcs/yqfkdt/ 202002/d5c495da742f4739b7f99339c3bd032f.shtml). All patients had the novel coronavirus pneumonia (NCP). The novel coronavirus belongs to lineage $\mathrm{B}$ of the genus betacoronavirus of the Coronavirus family, which includes SARS-CoV and MERS-CoV (Zhu et al., 2020). The 2019$\mathrm{nCoV}$ is the seventh member of the coronavirus family to infect humans (Chan et al., 2020). A recent study reported that fever, cough, myalgia or fatigue were common symptoms, and sputum production, headache, haemoptysis, and diarrhea were less common symptoms (Huang et al., 2020). All patients had pneumonia and about half developed dyspnea. One third of the patients were admitted to ICU (Huang et al., 2020). Compared with the $10 \%$ fatal rate of SARS$\mathrm{CoV}$ (Jiang et al., 2005) and 37\% fatal rate of MERS-CoV (Niu et al., 2018), 2019-nCoV is now the third lethal virus in the coronavirus family.

Our study describes the clinical characteristics of 12 2019nCoV infected patients. All patients were admitted to the Shenzhen Third People's Hospital, China. Clinical characteristics and blood biochemical indexes of 2019-nCoV patients were recorded and examined at the hospital. Patient respiratory samples, including throat swabs and bronchoalveoar lavage fluid (BALF), were collected and real-time PCR was used to confirm 2019-nCoV infection. We identified potential biomarkers of disease severity. Our results should help physicians to diagnose and treat patients infected with 2019-nCoV.

\section{RESULTS}

Twelve patients (four females and eight males) were admitted to Shenzhen Third People's hospital and confirmed to be infected with 2019-nCoV by Guangdong Center for Disease Control and Prevention (CDC) as of Jan 21, 2020. Of these patients, seven patients were over 60 years old. Notably, one adolescent case (case 7, 10 years old) was also found. Except for case 5 who lived in Shenzhen, 11 cases $(91.7 \%)$ lived or traveled to Wuhan city, and two family clusters were identified. Cases 1, 2, 6, and 7 within one family stayed in a hotel at a distance of about 2.5 miles away from Huanan Seafood Market for 6 days. On Dec 31, 2019 and Jan 1, 2020, they went to two local households for dinner. Cases 1, 2, and 6 developed fever on Jan 1, 2020, and case 6 also developed diarrhea. On Jan 4, 2020, they returned to Shenzhen city (Figure 1) where they lived with case 5, who subsequently developed fever, cough, and myalgia on Jan 8, 2020. Of note, none of the family members had an exposure history to indicate direct contact with seafood, live poultry, or other wild animals. Cases 10 and 11 were a couple who lived about 5.5 miles away from Huanan Seafood Market. They developed symptoms with fever and cough on Jan 4, 2020, and went to Shenzhen on Jan 13, 2020 (Figure 1). According to the possible exposure histories of the 12 patients, the estimated incubation period ranged from 1 to 13 days. Most of the cases developed influenza-like symptoms, and the intervals between illness onset and admission were between 5 and 16 days (Table 1). Six (50\%) cases had underlying diseases, including chronic heart disease, renal diseases, and diabetes. Pneumonia was the most common applications, followed by acute respiratory distress syndrome (ARDS) (including two cases with severe ARDS). All the patients received anti-viral (Ribavirin and Interferon) treatments, and six of them required mechanical ventilation, among whom cases 2,4 , and 10 received invasive mechanical ventilation. Corticosteroids and immunoglobulin were also used in cases 2, 4, and 10 (Table 1).

The complete blood count and blood biochemistry were measured for each patient either on the date of hospital admission, or at the earliest time-point thereafter. The most common laboratory abnormalities noted were hypoalbuminemia, lymphopenia, decreased percentage of lymphocytes (LYM) and neutrophils (NEU), elevated C-reactive protein (CRP) and lactate dehydrogenase (LDH), and decreased CD8 count (Table 2). The chest computed tomography (CT) scans of all patients showed ground-glass opacity around the shadow and pleural effusion, especially the lower and peripheral parts of the lungs (Figure 2; Figure S1 in Supporting Information). During the progression of the disease, the density of ground-glass opacity increased, and the range became larger, diffusing to the center and finally throughout the lungs (Figure 2). Case 4 developed fulminant myocarditis 5 days after illness onset. The biochemistry indexes associated with the function of heart, i.e., creatine kinase (CK), myoglobin (MYO), cardiac troponin 1 (Ctn1), brain natriuretic peptide (BNP), and CK myocardial band (CK-MB), were significantly elevated in case 4 (Table 2), and ultrasonic cardiogram results showed that the left ventricular ejection fraction (LVEF) was 32\%, and the left ventricular diameter (LV) was $61 \mathrm{~mm}$ on Jan 15, 2020 (5 days after illness onset) (Figure S2 in Supporting Information).

We used the Spearman correlation coefficient to calculate the correlation between 2019-nCoV virus cycle threshold 


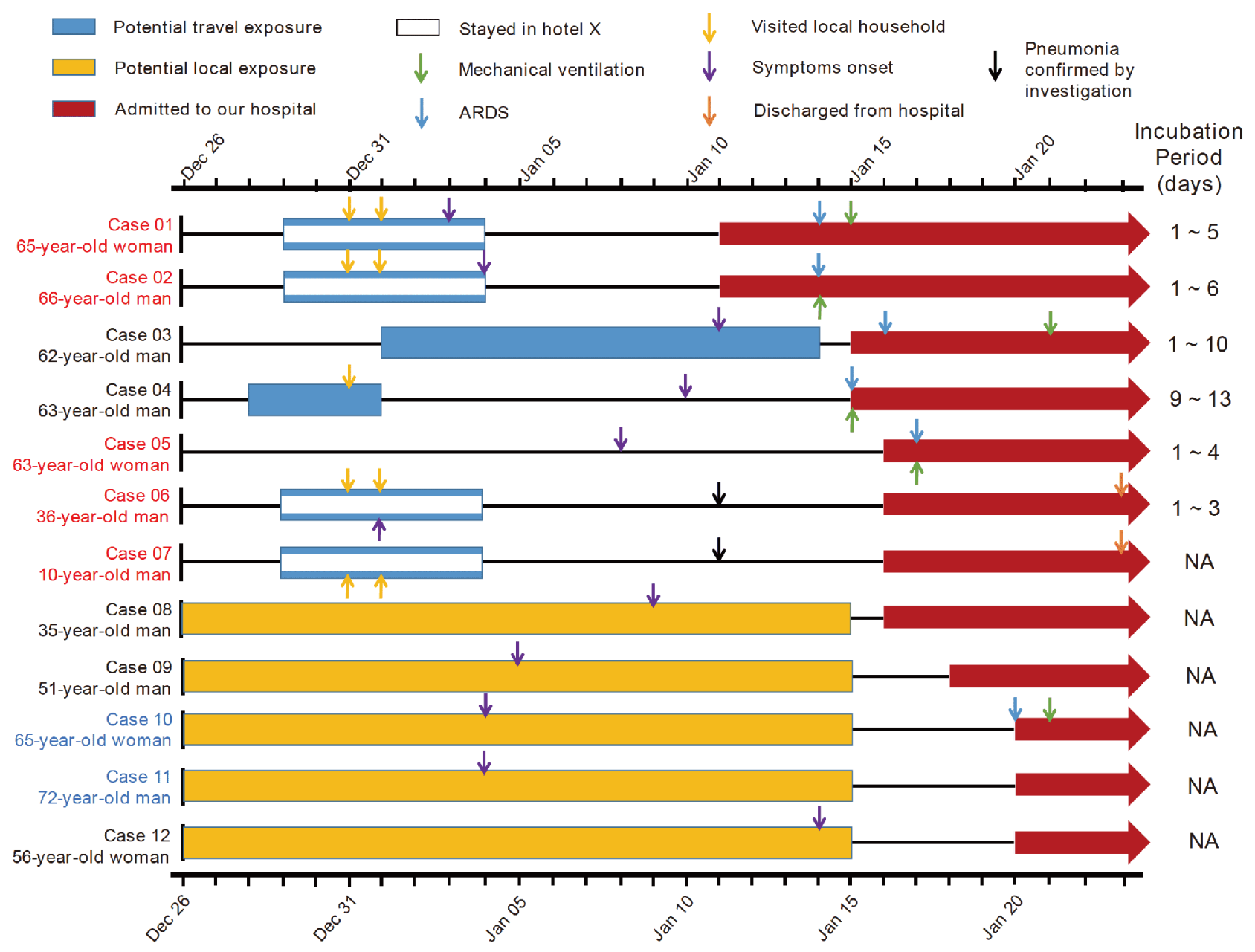

Figure 1 A timeline of events in human cases with 2019-nCoV. Patients are ordered in chronological order based on the date of admission to our hospital. Various milestones in the disease course are indicated with different graphics. Patients within a family were marked in red and blue, respectively.

$\left(C_{\mathrm{t}}\right)$ value, which is reciprocal to virus load, with clinical disease severity scores, Acute Physiology and Chronic Health Evaluation (APACHE) II Score, partial pressure of arterial oxygen $\left(\mathrm{PaO}_{2}\right)$ /fraction of inspired oxygen $\left(\mathrm{FiO}_{2}\right)$ ratios, and Murray scores of infected patients (Figure 3A; Figure S3 and Table S1 in Supporting Information). The viral load of 2019-nCoV detected from patients highly correlated with both ARDS index $\mathrm{PaO}_{2} / \mathrm{FiO}_{2}$ ratio and lung injury Murray score, but not with multiple organ dysfunction syndrome (MODS) score APACHE II (Figure 3A; Figure S3 in Supporting Information). This finding is consistent with the clinical features in this report that half of the infected patients developed ARDS and all patients were diagnosed with pneumonia, indicating that lung failure of the infected patients is the major dysfunction caused by $2019-\mathrm{nCoV}$ infection. Using the Spearman method, we further correlated the $C_{\mathrm{t}}$ value (viral load) of the $2019-\mathrm{nCoV}$ virus with biochemical and clinical indexes, and found that the levels of infectious diseases indicators albumin (ALB), and percentage of immunological cells of LYM, and NEU were significantly correlated with infected 2019-nCoV viral load
(Figure 3B).

Among the eight blood biochemistry indexes distinguished in blood samples of 2019-nCoV infected patients, specifically ALB, creatinine (CRE), LYM, LYM (\%), NEU (\%), LDH, CRP, and CD8, we found ALB, LYM, LYM (\%), NEU (\%), LDH, and CRP were highly linked to lung injury Murray score (Figure 4). Previous studies reported that hypoalbuminemia is a potent, dose-dependent predictor of poor outcome (Vincent et al., 2003). Therefore, albumin therapy might be a potential remedy for NCP.

We next statistically analyzed the link between the clinical and biochemical characteristics and disease severity, the definition of which is described in the second edition of medical guidelines of $2019-\mathrm{nCoV}$ infection from the National Health Commission of the People's Republic of China. We calculated the area under the curve (AUC) of the receiver operating characteristics (ROC) curve for characteristics from 2019-nCoV infected patients. The AUC value of the ROC curve of age was 1 , i.e., age could fully predict the disease severity of 2019-nCoV infected patients (Figure 5). The youngest "severe" patient in this Shenzhen cluster aged 
Table 1 Epidemiological and clinical features of human subjects hospitalized with 2019-nCoV infection ${ }^{\text {a) }}$

\begin{tabular}{|c|c|c|c|c|c|c|c|c|c|c|c|c|}
\hline Characteristics & Case 1 & Case 2 & Case 3 & Case 4 & Case 5 & Case 6 & Case 7 & Case 8 & Case 9 & Case 10 & Case 11 & Case 12 \\
\hline Age & 65 & 66 & 62 & 63 & 63 & 36 & 10 & 35 & 51 & 65 & 72 & 56 \\
\hline Sex & Female & Male & Male & Male & Female & Male & Male & Male & Male & Female & Male & Female \\
\hline Onset to admission (days) & 9 & 8 & 4 & 5 & 8 & 5 & 5 & 7 & 13 & 16 & 16 & 7 \\
\hline \multicolumn{13}{|l|}{ Initial symptoms } \\
\hline Fever & Yes & Yes & Yes & Yes & Yes & Yes & No & Yes & No & Yes & Yes & Yes \\
\hline Cough & Yes & Yes & Yes & Yes & Yes & Yes & No & Yes & Yes & Yes & Yes & Yes \\
\hline Headache & No & No & No & No & No & No & No & No & No & No & No & No \\
\hline Myalgia & Yes & Yes & No & No & Yes & No & No & No & Yes & No & No & No \\
\hline Chill & Yes & Yes & Yes & No & Yes & No & No & No & Yes & No & No & No \\
\hline Nausea or vomiting & No & Yes & No & No & No & Yes & No & No & No & No & No & No \\
\hline Diarrhea & No & No & Yes & No & No & Yes & No & No & No & No & No & No \\
\hline \multicolumn{13}{|l|}{ Underlying diseases } \\
\hline Chronic heart disease & Yes & Yes & Yes & No & No & No & No & No & No & No & Yes & No \\
\hline Chronic lung disease & No & No & No & Yes & No & No & No & No & No & No & No & No \\
\hline Chronic renal disease & No & No & Yes & No & No & No & No & No & No & No & Yes & No \\
\hline Chronic liver disease & No & No & No & No & No & No & No & No & No & No & No & No \\
\hline Diabetes & No & No & No & No & No & No & No & No & No & Yes & No & Yes \\
\hline Hypertension & Yes & Yes & No & No & No & No & No & No & No & No & Yes & No \\
\hline Cancer & No & No & No & No & No & No & No & No & No & No & No & No \\
\hline Bacterial co-infections & No & Yes & No & Yes & No & No & No & No & No & No & No & No \\
\hline \multicolumn{13}{|l|}{ Complications } \\
\hline Pneumonia & Yes & Yes & Yes & Yes & Yes & Yes & Yes & Yes & Yes & Yes & Yes & Yes \\
\hline ARDS & Yes & Yes & Yes & Yes & Yes & No & No & No & No & Yes & No & No \\
\hline Severe ARDS & No & Yes & No & Yes & No & No & No & No & No & No & No & No \\
\hline Respiratory failure & No & Yes & No & Yes & No & No & No & No & No & Yes & No & No \\
\hline Hepatic insufficiency & No & Yes & No & Yes & No & No & No & No & No & No & No & No \\
\hline Renal insufficiency & No & Yes & No & Yes & No & No & No & No & No & No & No & No \\
\hline Cardiac failure & No & No & No & Yes & No & No & No & No & No & No & No & No \\
\hline Shock & No & No & No & Yes & No & No & No & No & No & No & No & No \\
\hline \multicolumn{13}{|l|}{ Treatment } \\
\hline Antiviral agents & $\begin{array}{c}\text { Oseltamivir } \\
\text { Ribavirin } \\
\text { Interferon }\end{array}$ & $\begin{array}{l}\text { Oseltamivir } \\
\text { Ribavirin } \\
\text { Interferon }\end{array}$ & $\begin{array}{l}\text { Oseltamivir } \\
\text { Ribavirin } \\
\text { Interferon }\end{array}$ & $\begin{array}{l}\text { Oseltamivir } \\
\text { Ribavirin } \\
\text { Interferon }\end{array}$ & $\begin{array}{l}\text { Ribavirin } \\
\text { Interferon }\end{array}$ & $\begin{array}{l}\text { Ribavirin } \\
\text { Interferon }\end{array}$ & $\begin{array}{l}\text { Ribavirin } \\
\text { Interferon }\end{array}$ & $\begin{array}{l}\text { Ribavirin } \\
\text { Interferon }\end{array}$ & $\begin{array}{l}\text { Ribavirin } \\
\text { Interferon }\end{array}$ & $\begin{array}{l}\text { Ribavirin } \\
\text { Interferon }\end{array}$ & $\begin{array}{l}\text { Ribavirin } \\
\text { Interferon }\end{array}$ & $\begin{array}{l}\text { Ribavirin } \\
\text { Interferon }\end{array}$ \\
\hline Corticosteroid & No & Yes & No & Yes & No & No & No & No & No & Yes & No & No \\
\hline Mechanical ventilation & Yes & Yes & Yes & Yes & Yes & No & No & No & No & Yes & No & No \\
\hline Invasive mechanical ventilation & No & Yes & No & Yes & No & No & No & No & No & Yes & No & No \\
\hline Immunoglobulin & No & Yes & No & Yes & Yes & No & No & No & No & Yes & No & No \\
\hline
\end{tabular}

a) Severe ARDS, $\mathrm{PaO}_{2} / \mathrm{FiO}_{2}<100$.

56 years old. The amount of 2019-nCoV detected in patients' respiratory tracts and measured conversely in $C_{\mathrm{t}}$ value, as well as the lung injury Murray score and $\mathrm{PaO}_{2} / \mathrm{FiO}_{2}$ ratio, may very well predict the disease severity (Figure 5). Among the biochemical indexes, the AUC of ROC for the infection and tissue damage indicators, ALB, CRP, and LDH were 1, 0.938 , and 0.844 , respectively, and may also be potential predictors of disease severity. The AUCs for lymphocyte count and the percentage of lymphocytes and neutrophils were $1,0.844$, and 0.812 , respectively, and thus may also predict disease severity.

A recent article studied the 2019-nCoV genome sequence and predicted that the new coronavirus shared the ACE2 receptor of SARS-CoV (Xu et al., 2020), which is a critical enzyme in the renin-angiotensin system (RAS) (Huang et al., 2014; Zou et al., 2014). RAS plays important roles in maintaining blood pressure homeostasis (Forrester et al., 2018), and salt and fluid balance (Lin et al., 2017). ACE and ACE2 play different roles in RAS; ACE generates Angiotensin II, whereas ACE2 is a negative regulator of the system, decreasing Angiotensin II (Crackower et al. 2002). The abnormal increase of Angiotensin II was reported mostly associated with hypertension and heart failures (Packer and McMurray, 2017), and sometimes also lung and renal dysfunctions (Fröhlich et al., 2016; Kuba et al., 2005; Zou et al., 2014; Damman et al., 2018; Imai et al., 2005; Rai et al., 

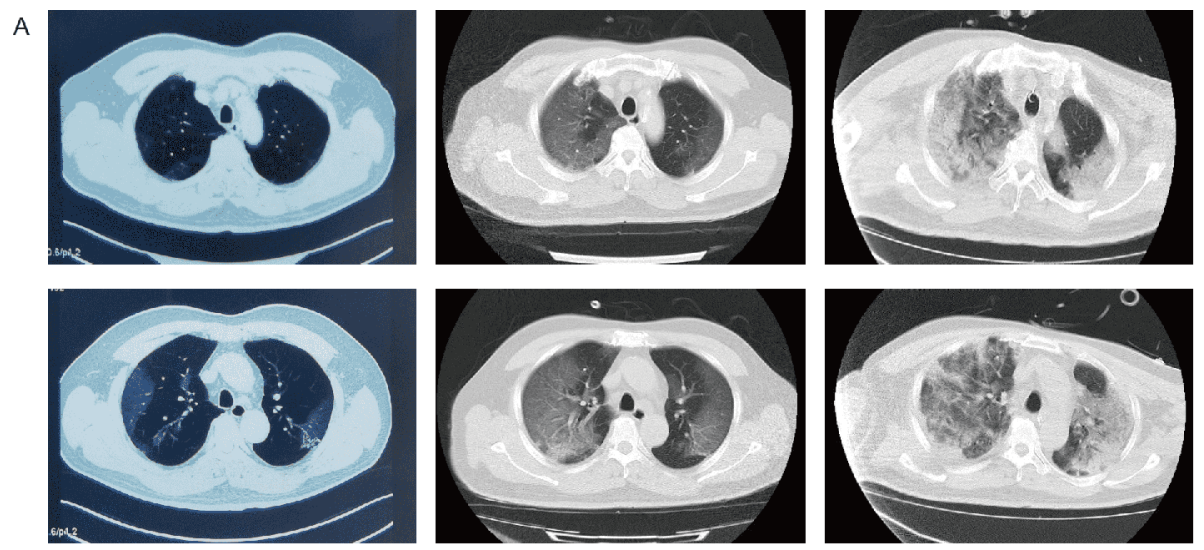

B

8 d.a.o

13 d.a.o

16 d.a.o
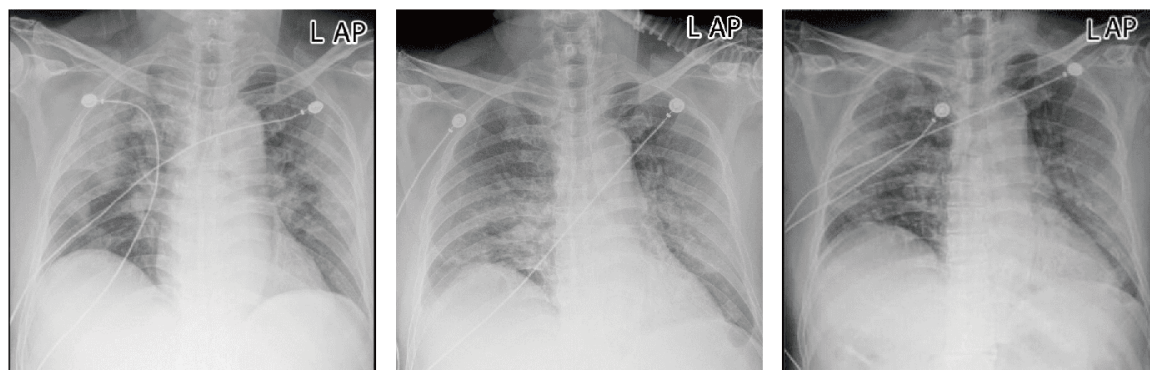

Figure 2 (Color online) Computed tomographic (CT) scans and chest radiographs of case 2. (A) CT scans and (B) chest radiographs of case 2 taken at indicated date are shown. d.a.o, days after illness onset.

Table 2 Clinical characteristics and laboratory results of subjects hospitalized with 2019-nCoV infection ${ }^{\text {a) }}$

\begin{tabular}{|c|c|c|c|c|c|c|c|c|c|c|c|c|c|}
\hline & Normal range & Case 1 & Case 2 & Case 3 & Case 4 & Case 5 & Case 6 & Case 7 & Case 8 & Case 9 & Case 10 & Case 11 & Case 12 \\
\hline $\mathrm{PaO}_{2} / \mathrm{FiO}_{2}$ & $400-500$ & 131 & 96 & 159 & 65 & 256 & 438 & 469 & 561 & 420 & 126 & 249 & 386 \\
\hline WBC $\left(\times 10^{9} \mathrm{~L}^{-1}\right)$ & $3.5-9.5$ & 4.31 & 5.24 & 3.85 & 6.79 & 6.71 & 13.55 & 6.72 & 4.62 & 4.94 & 5.89 & 4.99 & 3.98 \\
\hline LYM (\%) & $20-50$ & 20.4 & 23.1 & 21.6 & 3.8 & 11.5 & 17.5 & 56.4 & 34.4 & 29.4 & 7.1 & 19.8 & 20.9 \\
\hline $\operatorname{LYM}\left(\times 10^{9} \mathrm{~L}^{-1}\right)$ & $1.10-3.20$ & 0.88 & 1.21 & 0.83 & 0.26 & 0.77 & 2.37 & 3.79 & 1.59 & 1.45 & 0.42 & NA & 0.83 \\
\hline NEU (\%) & $40-75$ & 72.6 & 67.4 & 58.7 & 93 & 80.9 & 77.4 & 33.7 & 56.8 & 64.3 & 90.9 & 74.8 & 75.3 \\
\hline $\operatorname{NEU}\left(\times 10^{9} \mathrm{~L}^{-1}\right)$ & $1.8-6.3$ & 3.13 & 3.53 & 2.26 & 6.31 & 5.43 & 10.49 & 2.26 & 2.62 & 3.18 & 5.35 & 3.73 & 3 \\
\hline PLT $\left(\times 10^{9} \mathrm{~L}^{-1}\right)$ & $100-300$ & 161 & 118 & 121 & 119 & 215 & 250 & 196 & 236 & 184 & 118 & 99 & 152 \\
\hline $\operatorname{AST}\left(\mathrm{U} \mathrm{L}^{-1}\right)$ & $0-45$ & 26.7 & 33.6 & 26 & 107 & 26.2 & 29.3 & 34.7 & 28.9 & 37.7 & 52 & 42.1 & 36.1 \\
\hline $\operatorname{ALT}\left(\mathrm{U} \mathrm{L}^{-1}\right)$ & $0-45$ & 26.6 & 26.5 & 26 & 62 & 45.3 & 30 & 32.8 & 22.4 & 39.5 & 15.7 & 29 & 23.6 \\
\hline $\mathrm{TB}\left(\mu \mathrm{mol} \mathrm{L}{ }^{-1}\right)$ & $3.0-22$ & 10.8 & 9.5 & 9.1 & 6.2 & 11.6 & 12 & 8.5 & 7.8 & 7.8 & 8.4 & 9.6 & 5.9 \\
\hline $\operatorname{ALB}\left(\mathrm{g} \mathrm{L}^{-1}\right)$ & $40.0-55.0$ & 36.8 & 39.5 & 41.6 & 35.1 & 38.3 & 48.9 & 46.4 & 43.4 & 46.2 & 34.6 & 42.6 & 38.4 \\
\hline $\left.\operatorname{CRE}(\mu \mathrm{mol} \mathrm{L})^{-1}\right)$ & $58-110$ & 46.5 & 81.9 & 104 & 220 & 44.1 & 79.7 & 53 & 95.4 & 82.5 & 54.1 & 122 & 43.6 \\
\hline BUN $\left(\mathrm{mmol} \mathrm{L}^{-1}\right)$ & $3.2-7.1$ & 2.87 & 5.37 & 5.51 & 9.81 & 4.8 & 6.65 & 7.65 & 4.21 & 3.71 & 4.48 & 6.89 & 3.12 \\
\hline $\mathrm{CK}\left(\mathrm{U} \mathrm{L}^{-1}\right)$ & $50-310$ & 46 & 118 & 97 & 876 & NA & 111 & 70 & NA & NA & NA & NA & NA \\
\hline MYO (ng mL ${ }^{-1}$ ) & $0-110$ & 25.2 & 38.66 & 50.1 & 390.97 & 32.7 & 35 & 18.7 & 20.5 & 27 & 40.1 & 111.9 & 23.7 \\
\hline $\mathrm{Ctnl}\left(\mu \mathrm{g} \mathrm{mL}^{-1}\right)$ & $0-0.1$ & 0.012 & 0.012 & 0.012 & 11.37 & 0.012 & 0.012 & 0.012 & 0.012 & 0.012 & 0.014 & 0.012 & 0.012 \\
\hline $\mathrm{BNP}\left(\mathrm{pmol} \mathrm{L}^{-1}\right)$ & $0-23.1$ & 4.32 & 5.7 & 3.78 & 161.99 & NA & NA & NA & NA & NA & NA & NA & NA \\
\hline CK-MB (ng mL $\left.{ }^{-1}\right)$ & $0-2.37$ & 0.24 & 0.48 & $<0.22$ & 20.53 & $<0.22$ & 0.25 & 0.26 & $<0.22$ & $<0.22$ & 0.23 & 0.97 & $<0.22$ \\
\hline $\mathrm{LDH}\left(\mathrm{U} \mathrm{L}^{-1}\right)$ & $114.0-240.0$ & 662 & 593 & 169 & 720 & 696 & 491 & 475 & 558 & 476 & 1266 & 510 & 648 \\
\hline $\mathrm{CRP}\left(\mathrm{mg} \mathrm{L}^{-1}\right)$ & $<10$ & 52.6 & 38.6 & 52.95 & 89.94 & 53.6 & 5.8 & 5 & 35.6 & 13 & 33.2 & 85 & 28.4 \\
\hline PCT $\left(n g \mathrm{~mL}^{-1}\right)$ & $0-0.5$ & 0.048 & 0.04 & 0.095 & 9.18 & 0.031 & $<0.020$ & $<0.020$ & 0.029 & $<0.020$ & 0.077 & 0.218 & 0.033 \\
\hline $\mathrm{CD} 4\left(\right.$ count $\left.\mu \mathrm{L}^{-1}\right)$ & $34-52$ & 47.3 & 45.8 & 41.2 & 18.7 & 30.9 & NA & NA & NA & 50.2 & 34.9 & 50.7 & 43 \\
\hline CD8 (count $\mu \mathrm{L}^{-1}$ ) & $21-39$ & 16.7 & 16.5 & 11.6 & 10.9 & 23 & NA & NA & NA & 24.9 & 14.3 & 17 & 17.4 \\
\hline $\mathrm{CD} 4 / \mathrm{CD} 8$ & $0.9-3.6$ & 2.83 & 2.78 & 3.56 & 1.72 & 1.34 & NA & NA & NA & 2.02 & 2.45 & 2.98 & 2.47 \\
\hline
\end{tabular}

a) NA, not available. 

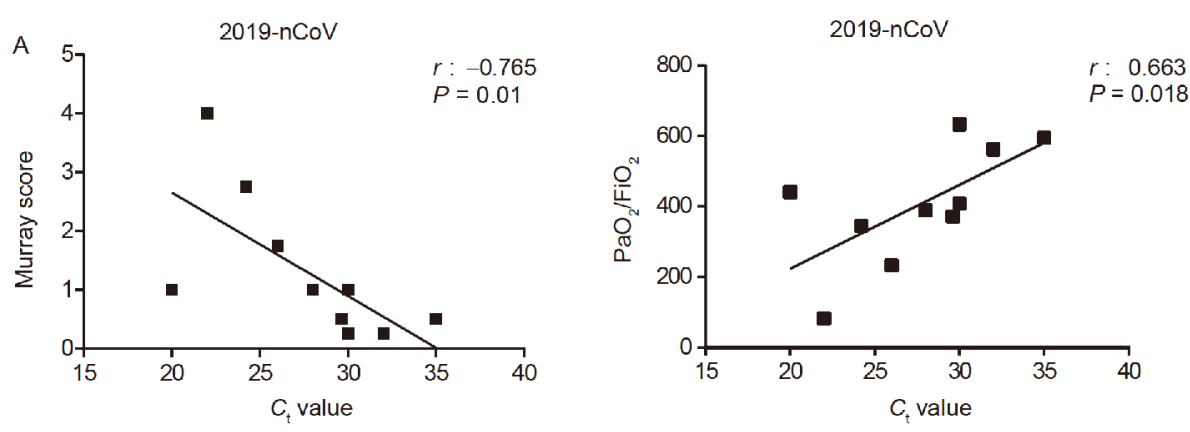

B
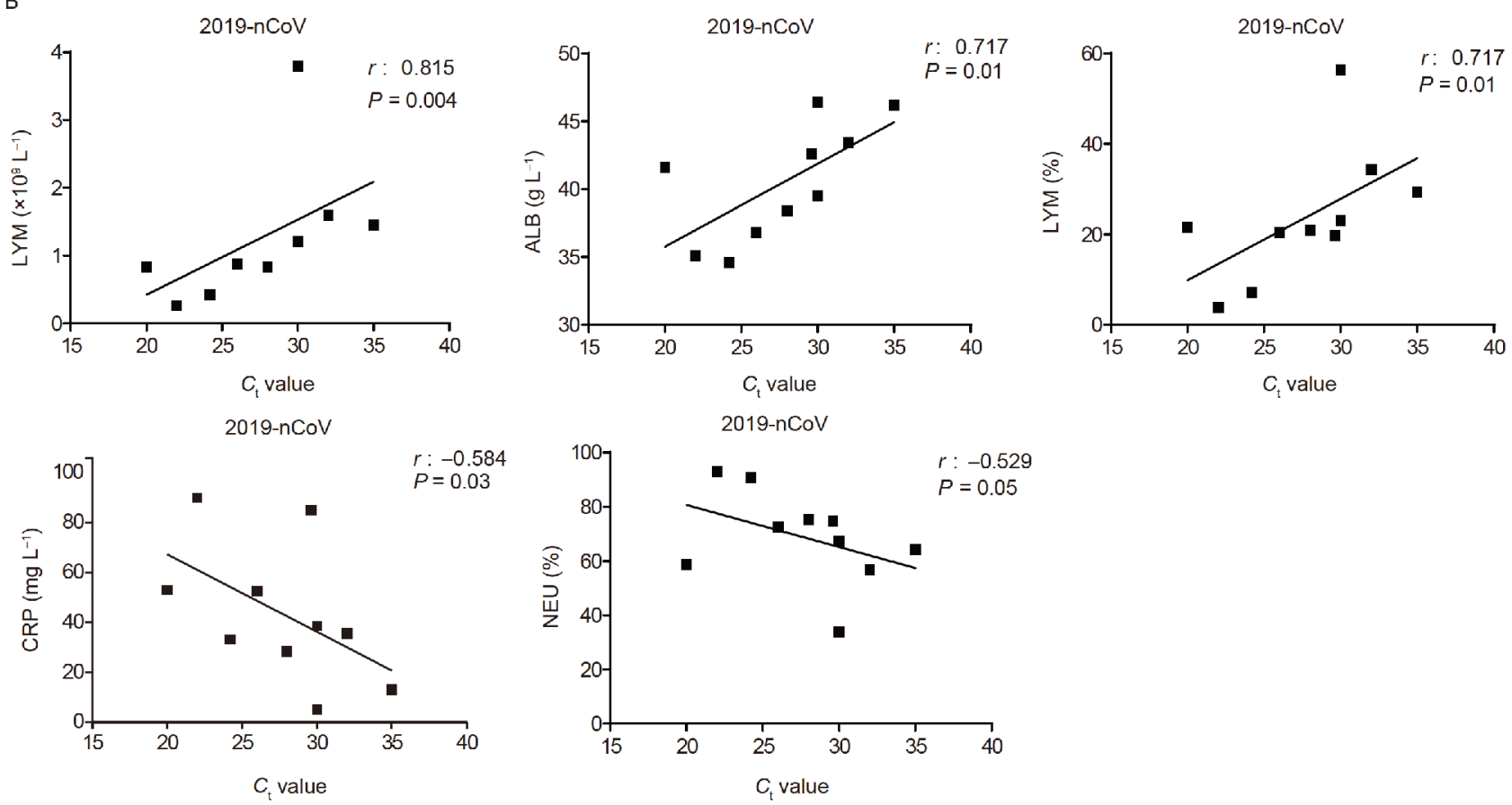

Figure 3 The $C_{\mathrm{t}}$ value of virus are highly correlated with clinical and laboratory manifestations in 2019-nCoV-infected patients. The $C_{\mathrm{t}}$ value of virus is highly correlated with (A) $\mathrm{PaO}_{2} / \mathrm{FiO}_{2}$ ratio, Murray score and (B) CRP, ALB, LYM (\%), LYM, NEU in 2019-nCoV-infected patients. The $C_{\mathrm{t}}$ value was detected available in 10 patients with 2019-nCoV infection. $\mathrm{PaO}_{2} / \mathrm{FiO}_{2}$ ratio, Murray score, ALB, LYM (\%), LYM, NEU, CRP, and LDH were detected from 12 2019-nCoV-infected patients. Spearman rank correlation analysis $(r)$ and $P$ values are provided in each graph.

2017; Torres et al., 2014). We measured the plasma level of Angiotensin II from 2019-nCoV infected patients and healthy individuals, the plasma levels of Angiotensin II from 2019-nCoV infected patients were significantly higher than that of healthy individuals (Figure 6A). Moreover, the level of Angiotensin II in 2019-nCoV patients was strongly associated with viral load and lung injury (Figure 6B and C), suggesting that the imbalanced renin-angiotensin system in patients was caused by 2019-nCoV and drugs of angiotensinconverting enzyme inhibitor (ACEI) and angiotensin receptor blocker (ARB) balancing RAS may be used repurposing on 2019-nCoV infected patients.

\section{DISCUSSION}

We report 12 cases with laboratory confirmed 2019-nCoV infections. All patients were admitted to the Shenzhen Third People's Hospital, Shenzhen, China. All patients were either living in or traveling to Wuhan from late December of 2019 to early January of 2020 , except case 5 who stayed in Shenzhen during the time period. Two family clusters were identified, and case 5 was in one of the family clusters with cases $1,2,6$, and 7 . This secondary infection of case 5 is one evidence of possible person-to-person spread of 2019-nCoV. Cases 1, 2, 6, and 7 might have been simultaneously infected in Wuhan, probably by a super-spreader contacting them in the hotel or home of their relatives, as five of their relatives in Wuhan developed similar symptoms (Chan et al., 2020). Since case 5 had disease onset 4 days after family members returning from Wuhan, the latency of 2019-nCoV might be as short as 1-4 days while the latency of most other patients was from 7 to 13 days (Figure 1). Two out of the 12 patients had no diagnosis of fever, including case 7 who had a clinical 

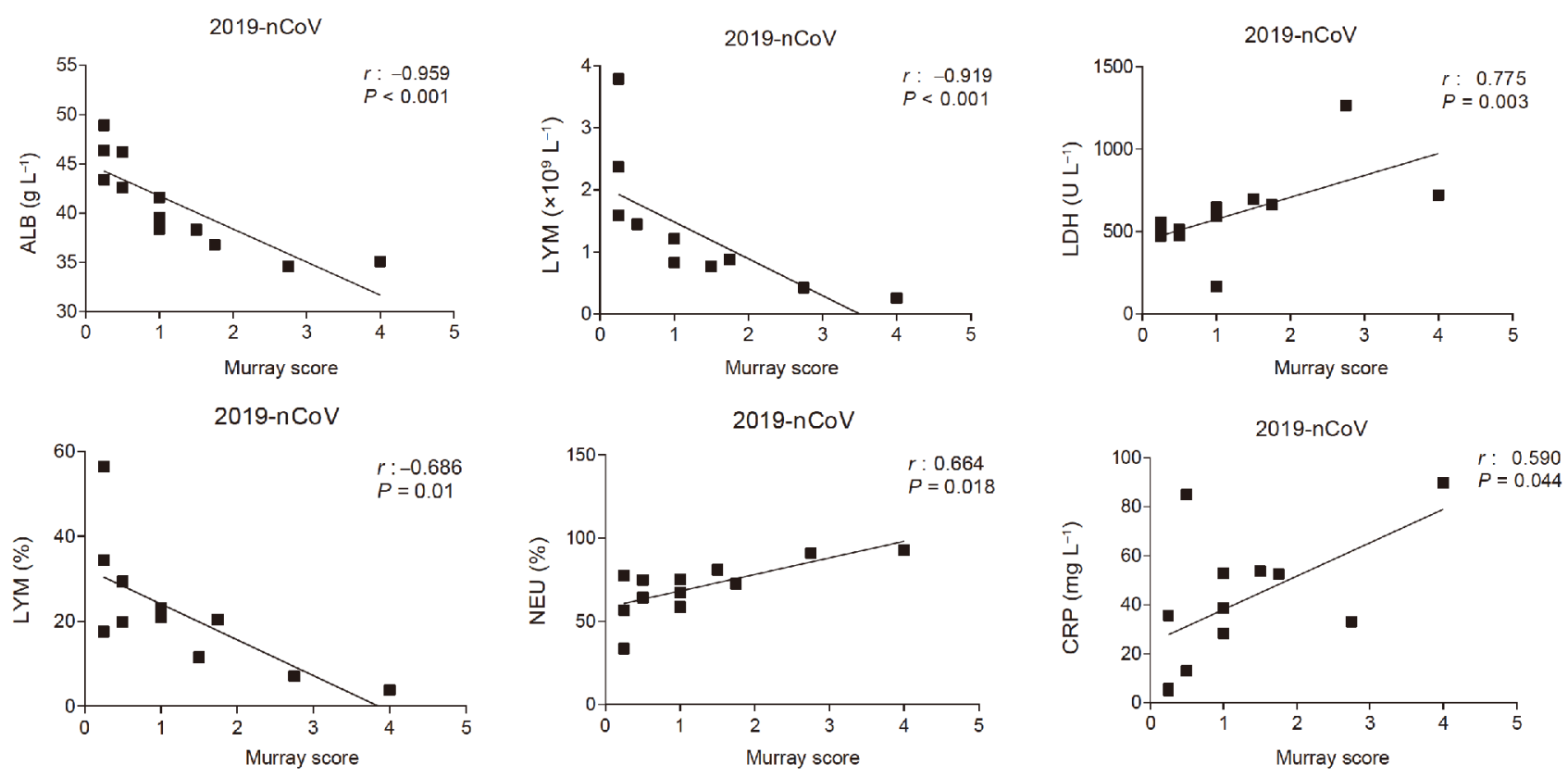

Figure 4 The Murray score is highly correlated with laboratory manifestations in 2019-nCoV-infected patients. The Murray score is highly correlated with ALB, LYM, LDH, LYM (\%), NEU (\%), and CRP. Murray score, ALB, LYM, LDH, LYM (\%), NEU (\%), and CRP were detected from 12 2019-nCoVinfected patients. Spearman rank correlation analysis $(r)$ and $P$ values are provided in each graph.

image check when accompanying family members to the hospital (Table 1). The risk of virus spread increased with non-fever patients, indicating that it is important to establish epidemiological history during clinical reception of the patients.

All samples from the respiratory tract, including throat swabs and BALF, were collected from 10 patients. Comparing the laboratory tests of these samples, the results of throat swabs and BALF collected at the same time from case 1,3 , and 4 were not consistent (Table S1 in Supporting Information), i.e., positive in BALF and negative in throat swabs, indicating that BALF was a more reliable sample for the 2019-nCoV test. It is worth noting that the laboratory test of BALF from case 8 was negative, but positive with throat swabs. Case 8 was discharged from our hospital after one week. Further studies are necessary to elucidate whether the foundation of disease was related to the location of the virus in the respiratory tract.

We found that the viral load was crucial in determining the disease severity, especially strongly correlated with lung injury Murray score (Figure 3A). Notably, the viral load from case 4 was very high when fulminant myocarditis also occurred (Table 2 and Figure 3). This high viral load lasted for one week, indicating that the early detection of high viral load may be associated with a high risk of fulminant myocarditis.

Our study provides a list of potential predictors for disease severity. For example, our study demonstrated that ALB and LYM counts were negatively correlated with the Murray scores, while CRP and LDH levels were positively correlated with the Murray scores in patients with 2019-nCoV (Figure 4). The Murray score was originally developed to assess the severity of acute lung injury in ARDS (Murray et al., 1988), and higher scores indicate greater severity in ARDS patients. This is consistent with previous studies showing that hypoalbuminemia, lymphopenia, and CRP $\geq 4 \mathrm{mg} \mathrm{dL}^{-1}$ were the predictive factors for pneumonia progression to respiratory failure in MERS-CoV infected patients and elevated lactate dehydrogenase was found with severe acute respiratory syndrome (SARS-CoV) infection on hospital admission (Ko et al., 2016; Liu et al., 2004; Leem et al., 2018). Therefore, the combinations of the hypoalbuminemia, lymphopenia, and high concentrations of CRP and LDH in 2019-nCoV infected patients upon hospital admission may predict more severe acute lung injury.

We discovered the markedly increased level of Angiotensin II in the plasma samples from 2019-nCoV infected patients. Our previous mice study has demonstrated that SARS-CoV could bind to its receptor ACE2, down-regulating its expressions, resulting in increased Angiotensin II level in mouse blood samples, signaling through angiotensin II receptor 1, and induced acute lung injury (Huang et al., 2014; Imai et al., 2005; Zou et al., 2014). We have also reported that avian influenza A virus $\mathrm{H} 5 \mathrm{~N} 1$ infected mice exhibited the acute lung injury through dysregulating RAS, and markedly elevation of Angiotensin II level in H7N9 infected patients was associated with the disease severity and outcomes (Guo et al., 2015; Huang et al., 2014). In addition, a retrospective cohort study in Texas, USA with hospitalized pneumonia patients reported that prior and inpatients use of 

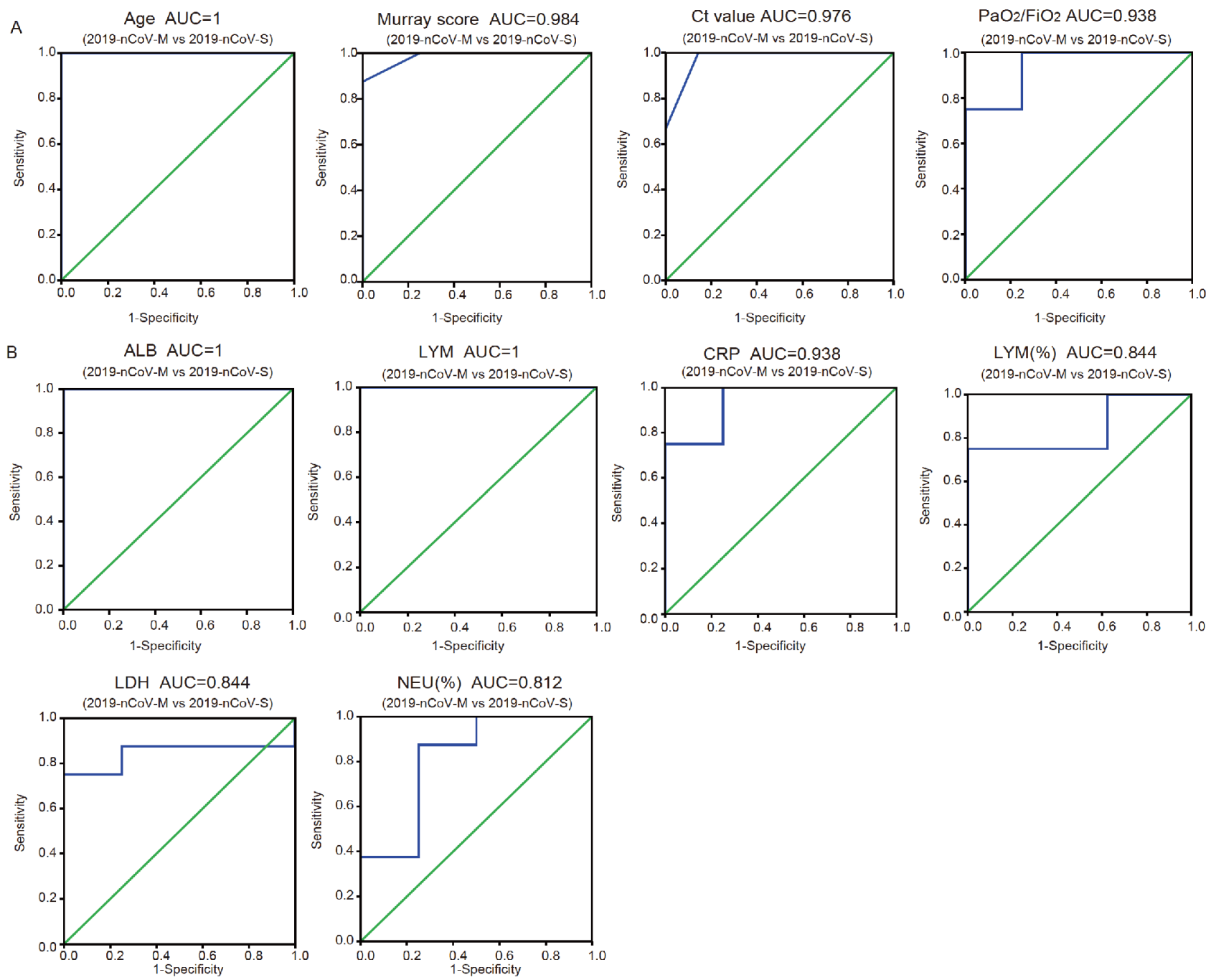

Figure 5 (Color online) Receiver operating characteristic (ROC) curve of clinical and biochemical indicators of 2019-nCoV-infected patients. (A) ROC curve of the age, Murray score, $\mathrm{Ct}$ value of $2019-\mathrm{nCoV}, \mathrm{PaO}_{2} / \mathrm{FiO}_{2}$ ratio and (B) ROC curve of the ALB, LYM, CRP, LYM (\%), LDH and NEU (\%) were calculated between four mild 2019-nCov-infected patients and eight severe 2019-nCov-infected patients. Detailed information is shown in Tables 1 and 2.
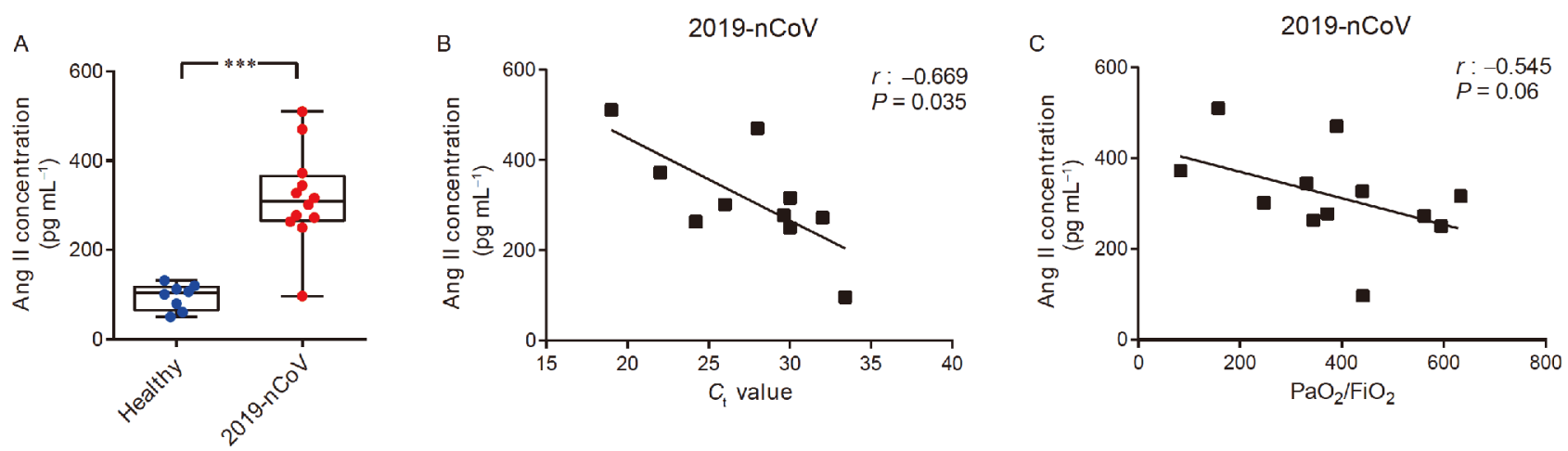

Figure 6 (Color online) Plasma angiotensin II levels are increased in 2019-nCoV-infected patients and correlated with viral $C_{\mathrm{t}}$ value and $\mathrm{PaO} / \mathrm{FiO}_{2}$ ratio. (A) Box plot of angiotensin II levels in plasma of healthy controls $(n=8)$ and 2019-nCov-infected patients $(n=12)$. $* * *, P<0.001$ (Mann-Whiney $U$ test). The correlation analysis between plasma angiotensin II levels and (B) viral $C_{\mathrm{t}}$ value, or $(\mathrm{C}) \mathrm{PaO}_{2} / \mathrm{FiO}_{2}$ ratio of patients with 2019-nCoV infection. The viral titers were detected available in 10 patients with 2019-nCoV infection. The $\mathrm{PaO}_{2} / \mathrm{FiO}_{2}$ ratio was detected from 12 2019-nCoV-infected patients. Spearman rank correlation analysis $(r)$ and $P$ values are provided in each graph.

ACE inhibitor and ARB were associated with the decreased mortality (Mortensen et al., 2012). Our previous studies demonstrated that ARB drugs, especially losartan, could effectively ameliorate mice acute lung injury induced by 
SARS-CoV and H5N1 influenza virus A (Kuba et al., 2005; Yan et al., 2015). These data suggest that ARB drugs may be used as treatment for ICU patients infected with 2019-nCoV.

The number of laboratory test confirmed patients is rapidly increasing. We hope that this report of the 12 cases in Shenzhen could provide useful information to prepare for potential pandemics of NCP.

\section{METHODS}

\section{Patients}

Twelve patients with pneumonia of unknown cause were admitted to the Shenzhen Third People's Hospital in Shenzhen, China between Jan 11 and Jan 20, 2020, and were confirmed to be infected with 2019-nCoV by Guangdong CDC (Center for Disease Control and Prevention). The age of the patient ranged between 10 and 72 years old. Of the 12 patients, three patients were in a critical condition and five were classified as severe, according to the guidelines of 2019-nCoV infection from the National Health Commission of the People's Republic of China. Bronchoalveolar lavage fluid (BALF) and throat swabs samples of 2019-nCoV infected patients were collected to detect virus titers. Blood samples from 2019-nCoV infected patients and healthy individuals working at Shenzhen Third People's Hospital were collected for measurement of plasma angiotensin II levels.

The study was performed in accordance with guidelines approved by the Ethics Committees from Shenzhen Third People's Hospital (SZTHEC2016001), and verbal informed consents were obtained from all patients or patients' family members.

\section{Data collection and analysis of clinical findings}

Clinical information, including complete blood counts, blood biochemistry, chest radiographs, and computed tomographic (CT) scans from 12 patients with laboratory-confirmed infection of 2019-nCoV were collected at the earliest time points possible upon hospitalization.

\section{Quantitative reverse transcription polymerase chain reaction}

Throat swabs and bronchoalveolar lavage fluid (BALF) were collected from the respiratory tract of the patients at various time points after hospitalization. Viral RNAs were extracted from samples using the QIAamp RNA Viral Kit (Qiagen, Heiden, Germany), and quantitative reverse transcription polymerase chain reaction (qRT-PCR) was performed using the primers and probes targeting the ORF1ab and $\mathrm{N}$ genes of 2019-nCoV as recommended by China CDC (http://ivdc. chinacdc.cn/kyjz/202001/t20200121_211337.html?from=timeline\&isappinstalled $=0$ ), using a commercial kit specific for 2019-nCoV detection (GeneoDX Co., Ltd., Shanghai, China). The specimens were considered positive if the $C_{\mathrm{t}}$ value was $\leq 37.0$, and negative if the results were undetermined. Specimens with a $C_{\mathrm{t}}$ higher than 37 were repeated. The specimen was considered positive if the repeat results were the same as the initial result and between 37 and 40. If the repeat $C_{\mathrm{t}}$ was undetectable, the specimen was considered negative.

\section{Quantification of hypoxia and lung injury}

Quantification of hypoxia and lung injury were carried out as previously reported (Bi et al., 2019; Yang et al., 2019). In brief, the partial pressure of oxygen $\left(\mathrm{PaO}_{2}\right)$ in arterial blood taken from the patients at various time points after hospitalization was measured by the ABL90 blood gas analyzer (Radiometer). The fraction of inspired oxygen $\left(\mathrm{FiO}_{2}\right)$ was calculated by the following formula: $\mathrm{FiO}_{2}=(21+$ oxygen flow (in units of $\mathrm{L} \mathrm{min}^{-1}$ ) $\times 4$ ) $/ 100$. The $\mathrm{PaO}_{2} / \mathrm{FiO}_{2}$ ratio (in units of $\mathrm{mmHg}$ ) was calculated by dividing the $\mathrm{PaO}_{2}$ value with the $\mathrm{FiO}_{2}$ value. $\mathrm{A} \mathrm{PaO}_{2} / \mathrm{FiO}_{2}$ ratio less than or equal to $100 \mathrm{mmHg}$ is considered one of the criteria for ARDS.

\section{Plasma angiotensin II measurement}

The plasma samples from 12 2019-nCoV infected patients were separated from blood samples in BSL-3 laboratory. The concentrations of plasma angiotensin II were measured by ELISA assay following the manufacturer's instructions (Cloud-clone, TX, USA).

\section{Statistical analysis}

We used the Mann-Whitney $U$ test to compare between two groups with continuous variables. The Spearman rank correlation coefficient was used for linear correlation analysis between two groups with continuous variables. ROC curves were calculated with AUC estimation for predictive analysis. We considered a $P$-value less than 0.05 as statistically significant. All the statistical analyses were performed with SPSS 16.0 for Windows (SPSS, Inc.).

Compliance and ethics The author(s) declare that they have no conflict of interest.

Acknowledgements The authors would like to thank a scientist who insists on being anonymous. The authors would also like to thank Shunwang Li and Xiaoyun Li who helped data analysis and making figures and tables. This work was supported by the National Science and Technology Major Project (2017ZX10103011 and 2017ZX10204401), Chinese Academy of Medical Sciences Innovation Fund for Medical Sciences (2017-I2M-1-009), Shenzhen Science and Technology Research and Development Project 
(JCYJ20180504165549581 and JCYJ20170413141236903), China Postdoctoral Science Foundation (2019T120147).

\section{References}

Bi, Y., Tan, S., Yang, Y., Wong, G., Zhao, M., Zhang, Q., Wang, Q., Zhao, X., Li, L., Yuan, J., et al. (2019). Clinical and immunological characteristics of human infections with H5N6 avian influenza virus. Clin Infect Dis 68, 1100-1109.

Chan, J.F.W., Yuan, S., Kok, K.H., To, K.K.W., Chu, H., Yang, J., Xing, F., Liu, J., Yip, C.C.Y., Poon, R.W.S., et al. (2020). A familial cluster of pneumonia associated with the 2019 novel coronavirus indicating person-to-person transmission: a study of a family cluster. Lancet, https://doi.org/10.1016/S0140-6736(20)30154-9.

Crackower, M.A., Sarao, R., Oudit, G.Y., Yagil, C., Kozieradzki, I., Scanga, S.E., Oliveira-dos-Santos, A.J., da Costa, J., Zhang, L., Pei, Y., et al. (2002). Angiotensin-converting enzyme 2 is an essential regulator of heart function. Nature 417, 822-828.

Damman, K., Gori, M., Claggett, B., Jhund, P.S., Senni, M., Lefkowitz, M. P., Prescott, M.F., Shi, V.C., Rouleau, J.L., Swedberg, K., et al. (2018). Renal effects and associated outcomes during angiotensin-neprilysin inhibition in heart failure. JACC-Heart Failure 6, 489-498.

Forrester, S.J., Booz, G.W., Sigmund, C.D., Coffman, T.M., Kawai, T., Rizzo, V., Scalia, R., and Eguchi, S. (2018). Angiotensin II signal transduction: an update on mechanisms of physiology and pathophysiology. Physiol Rev 98, 1627-1738.

Fröhlich, H., Nelges, C., Täger, T., Schwenger, V., Cebola, R., Schnorbach, J., Goode, K.M., Kazmi, S., Katus, H.A., Cleland, J.G.F., et al. (2016). Long-term changes of renal function in relation to ace inhibitor/ angiotensin receptor blocker dosing in patients with heart failure and chronic kidney disease. Am Heart J 178, 28-36.

Guo, J., Huang, F., Liu, J., Chen, Y., Wang, W., Cao, B., Zou, Z., Liu, S., Pan, J., Bao, C., et al. (2015). The serum profile of hypercytokinemia factors identified in H7N9-infected patients can predict fatal outcomes. Sci Rep 5, 10942.

Huang, C., Wang, Y., Li, X., Ren, L., Zhao, J., Hu, Y., Zhang, L., Fan, G., $\mathrm{Xu}, \mathrm{J}$., Gu, X., et al. (2020). Clinical features of patients infected with 2019 novel coronavirus in Wuhan, China. Lancet, https://doi.org/ 10.1016/S0140-6736(20)30183-5.

Huang, F., Guo, J., Zou, Z., Liu, J., Cao, B., Zhang, S., Li, H., Wang, W., Sheng, M., Liu, S., et al. (2014). Angiotensin II plasma levels are linked to disease severity and predict fatal outcomes in H7N9-infected patients. Nat Commun 5, 3595.

Imai, Y., Kuba, K., Rao, S., Huan, Y., Guo, F., Guan, B., Yang, P., Sarao, R., Wada, T., Leong-Poi, H., et al. (2005). Angiotensin-converting enzyme 2 protects from severe acute lung failure. Nature 11, 112-116.

Jiang, Y., Xu, J., Zhou, C., Wu, Z., Zhong, S., Liu, J., Luo, W., Chen, T., Qin, Q., and Deng, P. (2005). Characterization of cytokine/chemokine profiles of severe acute respiratory syndrome. Am J Respir Crit Care Med 171, 850-857.

Ko, J.H., Park, G.E., Lee, J.Y., Lee, J.Y., Cho, S.Y., Ha, Y.E., Kang, C.I., Kang, J.M., Kim, Y.J., Huh, H.J., et al. (2016). Predictive factors for pneumonia development and progression to respiratory failure in MERS-CoV infected patients. J Infection 73, 468-475.

Kuba, K., Imai, Y., Rao, S., Gao, H., Guo, F., Guan, B., Huan, Y., Yang, P., Zhang, Y., Deng, W., et al. (2005). A crucial role of angiotensin converting enzyme 2 (ACE2) in SARS coronavirus-induced lung injury. Nat Med 11, 875-879.

Leem, A.Y., Park, B., Kim, Y.S., Jung, J.Y., and Won, S. (2018). Incidence and risk of chronic obstructive pulmonary disease in a Korean community-based cohort. Int J Chron Obstruct Pulmon Dis 13, 509517.

Li, Q., Guan, X., Wu, P., Wang, X., Zhou, L., Tong, Y., Ren, R., Leung, K.
S.M., Lau, E.H.Y., Wong, J.Y., et al. (2020). Early transmission dynamics in Wuhan, China, of novel coronavirus-infected pneumonia. N Engl J Med, https://doi.org/10.1056/NEJMoa2001316.

Lin, Y.C., Lin, J.W., Wu, M.S., Chen, K.C., Peng, C.C., and Kang, Y.N. (2017). Effects of calcium channel blockers comparing to angiotensinconverting enzyme inhibitors and angiotensin receptor blockers in patients with hypertension and chronic kidney disease stage 3 to 5 and dialysis: A systematic review and meta-analysis. PLoS ONE 12, e0188975.

Liu, C.L., Lu, Y.T., Peng, M.J., Chen, P.J., Lin, R.L., Wu, C.L., and Kuo, H. T. (2004). Clinical and laboratory features of severe acute respiratory syndrome vis-a-vis onset of fever. Chest 126, 509-517.

Mortensen, E.M., Nakashima, B., Cornell, J., Copeland, L.A., Pugh, M.J., Anzueto, A., Good, C., Restrepo, M.I., Downs, J.R., Frei, C.R., et al. (2012). Population-based study of statins, angiotensin II receptor blockers, and angiotensin-converting enzyme inhibitors on pneumoniarelated outcomes. Clin Infect Dis 55, 1466-1473.

Murray, J.F., Matthay, M.A., Luce, J.M., and Flick, M.R. (1988). An expanded definition of the adult respiratory distress syndrome. Am Rev Respir Dis $138,720-723$.

Niu, P., Zhao, G., Deng, Y., Sun, S., Wang, W., Zhou, Y., and Tan, W. (2018). A novel human mAb (MERS-GD27) provides prophylactic and postexposure efficacy in MERS-CoV susceptible mice. Sci China Life Sci 61, 1280-1282.

Packer, M., and McMurray, J.J.V. (2017). Importance of endogenous compensatory vasoactive peptides in broadening the effects of inhibitors of the renin-angiotensin system for the treatment of heart failure. Lancet 389, 1831-1840.

Rai, A.K., Sanjukta, S., and Jeyaram, K. (2017). Production of angiotensin I converting enzyme inhibitory (ACE-I) peptides during milk fermentation and their role in reducing hypertension. Crit Rev Food Sci Nutrit 57, 2789-2800.

Tan, W., Zhao, X., Ma, X., Wang, W., Niu, P., Xu, W., Gao, G.F., and Wu, G. (2020). A novel coronavirus genome identified in a cluster of pneumonia cases-Wuhan, China 2019-2020. China CDC Weekly 2, $61-62$.

Torres, V.E., Abebe, K.Z., Chapman, A.B., Schrier, R.W., Braun, W.E., Steinman, T.I., Winklhofer, F.T., Brosnahan, G., Czarnecki, P.G., Hogan, M.C., et al. (2014). Angiotensin blockade in late autosomal dominant polycystic kidney disease. N Engl J Med 371, 2267-2276.

Vincent, J.L., Dubois, M.J., Navickis, R.J., and Wilkes, M.M. (2003). Hypoalbuminemia in acute illness: is there a rationale for intervention? Ann Surgery 237, 319-334.

Xu, X., Chen, P., Wang, J., Feng, J., Zhou, H., Li, X., Zhong, W., and Hao, P. (2020). Evolution of the novel coronavirus from the ongoing Wuhan outbreak and modeling of its spike protein for risk of human transmission. Sci China Life Sci, https://doi.org/10.1007/s11427-0201637-5.

Yan, Y.W., Liu, Q., Li, N., Du, J.C., Li, X., Li, C., Jin, N.Y., and Jiang, C.Y. (2015). Angiotensin II receptor blocker as a novel therapy in acute lung injury induced by avian influenza A H5N1 virus infection in mouse. Sci China Life Sci 58, 208-211.

Yang, Y., Wong, G., Yang, L., Tan, S., Li, J., Bai, B., Xu, Z., Li, H., Xu, W., Zhao, X., et al. (2019). Comparison between human infections caused by highly and low pathogenic H7N9 avian influenza viruses in Wave Five: Clinical and virological findings. J Infection 78, 241-248.

Zhu, N., Zhang, D., Wang, W., Li, X., Yang, B., Song, J., Zhao, X., Huang, B., Shi, W., Lu, R., et al. (2020). A Novel Coronavirus from Patients with Pneumonia in China, 2019. N Engl J Med, doi: 10.1056/NEJMoa2001017.

Zou, Z., Yan, Y., Shu, Y., Gao, R., Sun, Y., Li, X., Ju, X., Liang, Z., Liu, Q., Zhao, Y., et al. (2014). Angiotensin-converting enzyme 2 protects from lethal avian influenza A H5N1 infections. Nat Commun 5, 3594. 


\section{SUPPORTING INFORMATION}

Figure S1 Computed tomographic (CT) scans of human cases with 2019-nCoV. CT scans of cases 1 and 3-12 taken at indicated date are shown.

Figure S2 Assessment of the myocardial function in case 4. A and B, The ultrasonic cardiogram results. C, The left ventricular ejection fraction (LVEF) and the left ventricular diameter (LV) at the indicated date.

Figure S3 The correlation between APACHE II scores and viral $C_{\mathrm{t}}$ value in 2019-nCoV-infected patients. The viral titers were detected available in 10 patients with 2019-nCoV infection. APACHE II scores were detected from 12 2019-nCoV-infected patients. Spearman rank correlation analysis $(r)$ and $P$ values are provided in the graph.

Table S1 The $C_{\mathrm{t}}$ values of different sample types from the same case determined by qRT-PCR

The supporting information is available online at http://life.scichina.com and https://link.springer.com. The supporting materials are published as submitted, without typesetting or editing. The responsibility for scientific accuracy and content remains entirely with the authors. 